\title{
Overview of COVID 19 in Children with the Current Situation in Saudi Arabia Aisha Almutairi ${ }^{1}$, Abdullah Al-Shamrani ${ }^{2}$ \\ ${ }^{1}$ Department of Pediatrics, College of Medicine, Qassim University, ${ }^{2}$ Prince Sultan Medical Military City (PSMMC), Department of Pediatric, Riyadh, Saudi Arabia \\ *Corresponding author: Aisha Thwayb Almutairi, Mobile: 00966503142618, Email: aishaalmutairi@qumed.edu.sa
}

\begin{abstract}
Background: Severe acute respiratory syndrome coronavirus-2 (SARS-CoV-2), first identified in Wuhan, China, has resulted within the coronavirus disease 19 (COVID-19) pandemic that has spread to 210 countries worldwide. At the time of scripting this review, 76,726 people had been infected with and 411 died from SARS-CoV-2 in Kingdom of Saudi Arabia. COVID-19 has deeply impacted the lives of millions globally, either directly or as a results of the preventive measures instituted to regulate the spread of the disease. Research groups worldwide are working hard to develop sensitive and specific diagnostic tools and effective vaccines. This review aimed to supply relevant COVID19 research data obtained from a literature review. Conclusion: We believe that our study makes significant contributions to the literature because it provides a condensed, authoritative presentation of the numerous clinical presentations, diagnoses, treatments, and patient management strategies for COVID-19. It also as reports on this COVID-19 situation in Kingdom of Saudi Arabia.
\end{abstract}

Keywords: COVID 19, COVID 19 diagnostic testing, severe acute respiratory syndrome, coronavirus 2.

\section{INTRODUCTION}

In December 2019 in Wuhan, China, some patients complained of fever and dry cough, and their laboratory test results indicated either normal or decreased leukocyte counts. These patients were initially diagnosed with "fever of unknown origin with pneumonia", and their numbers continued to extend ${ }^{[1]}$. The causative organism of this infected pneumonia was identified as severe acute respiratory syndrome coronavirus 2 (SARS- CoV- 2). The World Health Organization named the disease associated with SARSCoV-2 infections as coronavirus disease 2019 (COVID19). Coronaviruses (CoVs) are an oversized family of RNA viruses that cause illnesses ranging from a common cold to severe diseases such as Middle East Respiratory Syndrome (MERS) and Severe Acute Respiratory Syndrome (SARS) ${ }^{[2]}$. SARS-CoV- 2 is extremely infectious, and this virus has spread rapidly to other countries. As of May 5, 2020, the globally confirmed cases with COVID-19 were 3,600,106 and 251,898 COVID-19-related deaths. The World Health Organization declared the COVID-19 epidemic as a pandemic on March 12, $2020^{[3]}$. Currently, COVID-19 has spread across 210 countries worldwide. As of May $26^{\text {th }}, 2020,76,726$ individuals in Saudi Arabia had been infected with SARS-CoV-2 and 411 individuals had died. Till now no specific therapeutic agents or vaccines for COVID-19 are available. Clinical trials evaluating the efficacy of remdesivir and favipiravir on COVID-19 are currently underway ${ }^{[4]}$. The number of children who reported having COVID- 19 has gradually become clearer. Moreover, the management of neonates born to mothers with COVID- 19 has become a further concern; there are few neonates born to mothers with COVID 19 who had positive SARS COV-2 PCR on screening. Due to their developing immune system, children and infants are susceptible to upper respiratory tract infection; however, the reasons for fewer reported cases of COVID-19 among the pediatric population remain unclear. Overall, pediatric patients have been reported to have a good prognosis generally, with an average hospital stay of 12.9 days ${ }^{[5]}$. To help facilitate the most effective management for patients with COVID-19, we sought to proceed with a narrative review of all original research related to COVID 19, making it available to everyone. Speed has been important, and to stay pace with the rapid production of new evidence, we have proceeded with informal, rapid, evidence synthesis.

Our review provides a condensed, authoritative presentation of the varied clinical presentations, diagnoses, and management strategies for patients with COVID-19. It also describes the current situation regarding COVID-19 in Saudi Arabia.

\section{Etiology and pathogeneses of COVID- 19}

SARS- CoV- 2, a single- stranded RNA virus, is a member of the genus Beta coronavirus and belongs to the subgenus Sarbecovirus. SARS- CoV- 2 particles contain spikes and envelopes, and the virions are round, oval, or pleomorphic with breadths of around 60-140 $\mathrm{nm}$. The structural proteins are encoded with four structural genes, namely, spike (S), envelope (E),

This article is an open access article distributed under the terms and conditions of the Creative Commons Attribution (CC BY-SA) license (http://creativecommons.org/licenses/by/4.0/) 
membrane (M), and nucleocapsid (N) genes. Transcribed non-structural proteins include ORF1ab, ORF3a, ORF6, ORF7a, ORF10, and ORF8. This novel coronavirus $(\mathrm{CoV})$ is extremely kind of like to a $\mathrm{CoV}$ identified in bats and has been found to own significant similarity with the SARS virus ${ }^{[6]}$.

SARS-CoV- 2 has been shown to have weak resistance at a temperature of $56{ }^{\circ} \mathrm{C}$ for half hour, and $75 \%$ ethanol solution, chlorine-containing disinfectant, and peracetic acid are reported to inactivate SARS-

CoV- 2. SARS-CoV-2 has been shown to stay viable and infectious in aerosols for three hours and on surfaces for up to three days. It is more stable on plastic and stainless steel surfaces than on copper and cardboard surfaces, and after application onto these surfaces, the virus was viable and detectable at $72 \mathrm{~h}, 48 \mathrm{~h}, 4 \mathrm{~h}$, and 24 h, respectively ${ }^{[7]}$.

Studies have reported that SARS-CoV-2 enters epithelial cells through the spike (S) protein and interacts with the human angiotensin-converting enzyme 2 (ACE2) receptor, which is highly expressed on alveolar type 2 progenitor cells, together with esophageal upper epithelial cells and enterocytes of the ileum and colon, leading to human infection. Immaturity of ACE2 receptors in children may explain the low prevalence of COVID-19 in this age group. One study reported that ORF1ab, ORF10, and ORF3a are coordinated in attacking the heme of the 1-beta chain of hemoglobin to dissociate iron to create porphyrin, whereas ORF8 and surface glycoprotein were found to function together with porphyrin to create a complex. This mechanism inhibits the regular metabolic pathway of heme leading to the clinical presentation of COVID-19.

This attack results in decrease hemoglobin available to move oxygen and carbon dioxide. The impaired gaseous exchange within the lungs eventually end up in highly intense inflammation. This may explain the radiological changes observed on lung radiographic images. Patients with diabetes and elderly have higher glycated hemoglobin, and glycated hemoglobin levels have shown to be decreased due to this attack, with unstable blood glucose levels among infected patients reported ${ }^{[8]}$.

\section{SARS-CoV-2 transmission}

The current data shows that the major transmission routes for SARS-CoV-2 are via droplet, direct contact, and aerosol transmissions. Infection can also occur when hands touch a contaminated surface then comes into contact with the eyes, nose, or mouth. Droplets typically do not travel more than six feet (approximately two meters) and do not linger in the air. Evidence of transmission by asymptomatic individuals has been reported. A fecal- oral transmission route cannot be dismissed, as the SARS- CoV- 2 has been reported in the fecal samples of patients in the United States and in
China ${ }^{[9]}$. However, a study from Germany did not identify any live, virus in stools despite detectable viral RNA, suggesting that the detectable viral RNA may be due to viral debris rather than active virus ${ }^{[10]}$. Further studies are required to confirm this finding. Several cases of neonates with COVID-19 have been reported; however, there has been no robust evidence on vertical transmission or transmission in breast milk of SARSCoV-2. In a study of six neonates' babies and their infected mothers, tested samples from amniotic fluid, cord blood, were negative for SARS- CoV- $2^{[11]}$. The role of children in passing the disease to others is unknown, but it seems likely they do not play a significant role in transmission. Moreover, studies of family clusters have revealed children were unlikely to be the index case ${ }^{[12]}$.

\section{COVID-19 case definition}

\section{A person in contact with COVID-19}

Being in contact with someone with COVID-19 is defined as an asymptomatic child or adult who has been in close contact with a person with COVID-19, within 14 days of development of his/her symptoms. Being 'in contact' is defined as:

a) Staying in the same closed environment as a person with COVID-19.

b) Traveling near someone with COVID-19 in any form of transportation

c) healthcare-associated exposure, including staying in the same close environment as a confirmed patient with COVID-19, or having visited a patient with confirmed COVID-19.

\section{A suspected patient with COVID-19 in Saudi Arabia} A suspected patient with COVID-19 is defined as a patient presenting with acute respiratory symptoms (fever, cough, or shortness of breath) and having had a minimum one of the following epidemiological criteria in the 14 days before symptom onset:

a) a history of recent travel abroad

b) a history of having visited or resided in one of the identified high-risk areas in Saudi Arabia

c) a history of having had close physical contact prior to symptom onset with a confirmed patient with COVID-19

d) history of having had close contact with someone working at or attending a healthcare facility where patients with confirmed COVID-19 have been admitted

NB: Some patients may present with gastrointestinal symptoms prior to the development of fever and respiratory symptoms. ${ }^{[13]}$

OR a patient with unexplained severe acute respiratory illness (pneumonia or ARDS) requiring intensive care 
unit (ICU) admission and fulfilling the following conditions:

a) Laboratory test results for influenza, respiratory syncytial virus (RSV), and MERS are shown to be negative

b) No clinically observed improvement.

\section{A patient confirmed to have COVID-19}

A patient confirmed to have COVID-19 is defined as a suspected patient who then tests positive for COVID-19, in accordance with testing standards and irrespective of clinical signs or symptoms ${ }^{[13]}$.

\section{Clinical presentation of COVID-19}

The exact incubation period for SARS-CoV-2 infection has not yet been determined; however, it has been estimated to be approximately $2-14$ days, with a mean of 5.2 days. The incubation period may reach 27 days, and the symptoms of COVID-19 have been reported to correlate with patient age ${ }^{[14]}$. Huang et al.'s study of 41 patients showed that the patients presented with the following clinical symptoms: fever (98\%), cough $(76 \%)$, and myalgia (44\%). Other symptoms included sputum production (28\%), headache (8\%), hemoptysis $(5 \%)$, and diarrhea $(3 \%)$, whereas dyspnea was reported to have developed in $55 \%$ of patients. ${ }^{[2]} \mathrm{In}$ Wang et al.'s study of 138 patients, the most commonly reported symptoms were fever (98.6\%), fatigue (69.6\%), and dry cough $(59.4 \%)^{[15]}$. Chen et al.'s study of 99 patients reported fever (83\%), cough (82\%), shortness of breath $(31 \%)$, followed by other symptoms such as myalgia $(11 \%)$, confusion $(9 \%)$, headache $(8 \%)$, sore throat $(5 \%)$, rhinorrhea $(4 \%)$, chest pain $(2 \%)$, diarrhea $(2 \%)$, and vomiting $(1 \%)^{[16]}$.

$X u$ et al. reported on 62 patients with SARS-CoV2 infections in Zhejiang province, China, and identified the following symptoms: cough (81\%), fever (77\%), myalgia (52\%), and headache (34\%) ${ }^{[17]}$. Guan et al. reported their findings concerning 1099 patients with COVID-19-related pneumonia in Wuhan, China. The most common clinical features at the onset of illness were: fever (88\%), fatigue (38\%), dry cough (67\%), myalgia (14.9\%), and dyspnea (18.7\%). Pneumonia was reported to be the most common clinical diagnosis. They reported that, for this patient group, breathing difficulties developed after a median five days of illness, and ARDS developed in $3.4 \%$ of the reported patients. Headache, sore throat, rhinorrhea, and gastrointestinal symptoms were reported to have occurred in $2.3-5 \%$ of their study patients ${ }^{[18]}$. In summary, the signs and symptoms vary; however, over the course of the disease, most patients with COVID-19 are likely to present the following: fever (83-99\%), cough (59-82\%), fatigue (44-70\%), anorexia (40-84\%), shortness of breath (31-40\%), sputum production (28-33\%), and myalgia (11-35).

Table 1: Clinical features of COVID-19 $(2,14,18,19,20,21)$

\begin{tabular}{|c|c|c|c|c|c|c|}
\hline & $\begin{array}{l}\text { C. Huang } \\
\text { et al } \\
41 \text { patients[2] }\end{array}$ & $\begin{array}{l}\text { Li Q Guan } \\
\text { etal } \\
171 \\
\text { Patients[14] }\end{array}$ & $\begin{array}{l}\text { Guan WJ } \\
\text { et al } \\
1099 \\
\text { patients[18] }\end{array}$ & $\begin{array}{l}\text { Wenjun } \mathrm{Du} \\
\text { et al., } \\
14 \text { patients } \\
{[19]}\end{array}$ & $\begin{array}{l}\text { Qiu } \mathrm{H} \text { et al } \\
36 \text { patients } \\
{[20]}\end{array}$ & $\begin{array}{l}\text { Shekerdemia LS } \\
\text { et al } \\
48 \text { patients } \\
\text { (PICU) }[21]\end{array}$ \\
\hline Median age & 8.2 & $6.7 y$ & $<15$ & 6.2 & 8 & 13 \\
\hline Cough & & 48.5 & $67.8 \%$ & 21.5 & 17 & $73 \%$ Respiratory \\
\hline $\begin{array}{l}\text { Pharyngeal } \\
\text { erythema }\end{array}$ & 17 & 46.2 & - & 7.1 & 4 & - \\
\hline Fever & 36 & 41.5 & 88 & 35.7 & 36 & - \\
\hline Diarrhea & 8 & 15 & $2.3-5$ & 15 & 6 & 2\% Gastrointestinal \\
\hline Headache & 24 & $0 \%$ & $2.3-5$ & 7.1 & 8 & $4 \%$ Neurology \\
\hline Myalgia & - & 7.6 & - & 7.1 & - & - \\
\hline Rhinorrhea & - & 7.6 & $2.3-5$ & 7.1 & - & - \\
\hline Vomiting & 8 & 6.4 & $2.3-5$ & 0 & 6 & - \\
\hline $\begin{array}{l}\text { Nasal } \\
\text { congestion }\end{array}$ & 9 & 5.3 & $2.3-5$ & - & - & - \\
\hline Tachypnea & 8 & 28.7 & 15.8 & 0 & 3 & $4 \%$ Circulatory \\
\hline others & $\begin{array}{l}\text { Sore throat } 6 \\
\text { Hemoptysis } \\
5 \% \\
\text { Sputum } \\
28 \%\end{array}$ & $\begin{array}{l}\text { Tachycardia } \\
42.1 \\
\text { Sat }<92: 2.3\end{array}$ & - & $\begin{array}{l}\text { Clinical } \\
\text { Features } \\
\text { were mild }\end{array}$ & - & $\begin{array}{l}\text { Medical complex, } \\
\text { Immunosuppression } \\
\text { and Malignancy } \\
\text { were the commonest } \\
\text { underline causes }\end{array}$ \\
\hline
\end{tabular}


In contrast to adults, pediatric COVID-19 typically causes mild symptoms, mainly involving the upper respiratory tract ${ }^{[22]}$. In China, only $1-5 \%$ of children $<10$ years have been reported to have COVID-19 ${ }^{[4]}$. Children, and infants in particular, are less frequently exposed to SARS-CoV-2 [20, 23].

Moreover, symptoms have been reported to resolve in less than two weeks. According to the China-World Health Organization, children with COVID-19 represent $<2.4 \%$ of the total patient population with COVID-19. In contrast to RSV and influenza, children with COVID-19 are at greater risk of hospital admission, and immature childhood immunity is considered to be a contributing factor. In a study involving 36 pediatric patients with COVID-19 (age, $<16$ years), confirmed as polymerase chain reactionpositive, $28 \%$ of the patients were asymptomatic, despite contact with an infected person or exposure to an epidemic area; none of the patients required ventilation and there were no deaths ${ }^{[20]}$.

The most common symptoms were similar to those of adult patients with COVID-19, namely, cough and/or fever, and bronchopneumonia was the most common clinical diagnosis in $53 \%$ of patients reported ${ }^{[20]}$. In a large retrospective study by Dong et al ${ }^{[22]}$.involving 2,143 pediatric patients, $34.1 \%$ were confirmed as COVID-19positive, with a median age of 7 years, and with no sex differences. In total, $90 \%$ of the patients in that study were asymptomatic (Table 2).

The clinical pattern in children has not been fully elucidated, although COVID-19 appears to be more benign in children ${ }^{[22,23]}$. In adults, age is the strongest risk factor for COVID-19-related severe illness, complications, and death. In the absence of any underlying medical conditions, a case fatality rate of $0.9 \%$ has been reported; however, this rate is considerably higher for patients with comorbidities, such as cardiovascular disease, diabetes mellitus, chronic respiratory disease, hypertension, and cancer $^{[2,4]}$.

In pediatric patients, this factor remains an area of ongoing research. Infants and children with underlying medical conditions and special healthcare requirements are considered to be at higher risk for severe illness; however, more data is required to confirm this ${ }^{[22]}$. Few reported pediatric patients have developed hypoxia or have required ventilator support ${ }^{[24]}$.

A newborn infection has been reported, and minor symptoms such as tachypnea and skin rash were found to have resolved spontaneously ${ }^{[25]}$. When compared to children with SARS, patients with COVID-19 demonstrated much milder disease in terms of the prevalence of fever, cough, and pneumonia in terms of the number of severe cases. Moreover, they had fewer upper respiratory symptoms (e.g., cough and pharyngeal congestion) but a greater prevalence of pneumonia when compared to those with H1N1 influenza.

Patients with COVID-19 present with flu-like symptoms including fever and cough, typically starting with fever, then followed with a cough that is less likely to proceed to pneumonia in children compared to that in elderly patients. Within a week, shortness of breath may occur and approximately $20 \%$ of these patients may require admission. Rarely, they present with a runny nose and sneezing ${ }^{[22]}$.

Table 2. Classification of Disease Severity in Children [22]

\begin{tabular}{|c|c|c|c|c|c|}
\hline & $\begin{array}{c}\text { Asymptomatic } \\
4 \%\end{array}$ & Mild (51\% & Moderate (39\%) & Severe (5\%) & Critical (0.6\%) \\
\hline Criteria & $\begin{array}{l}\text { No clinical } \\
\text { signs or } \\
\text { symptoms with } \\
\text { normal chest } \\
\text { imaging }\end{array}$ & $\begin{array}{l}\text { Symptoms of } \\
\text { acute upper } \\
\text { respiratory tract } \\
\text { infection and/or } \\
\text { mild lower } \\
\text { respiratory tract } \\
\text { infection; may } \\
\text { also include } \\
\text { fatigue, } \\
\text { myalgia, and } \\
\text { gastrointestinal } \\
\text { symptoms. } \\
\text { Mild or no } \\
\text { increase work } \\
\text { of breathing } \\
\text { No } \mathrm{O}_{2} \\
\text { requirement }\end{array}$ & $\begin{array}{l}\begin{array}{l}\text { Clinical and/or } \\
\text { radiological signs } \\
\text { of pneumonia } \\
\text { present }\end{array} \\
\text { Respiratory rate: } \\
\text { increased }\end{array}$ & $\begin{array}{l}\text { Moderate to severe } \\
\text { work of breathing } \\
\text { or significant } \\
\text { hypoxia: } \\
\text { warranting ICU } \\
\text { Admission for non- } \\
\text { invasive ventilation }\end{array}$ & $\begin{array}{l}\text { Pediatric acute } \\
\text { respiratory } \\
\text { Distress Syndrome } \\
\text { (pARDS) necessitating } \\
\text { invasive mechanical } \\
\text { ventilation } \\
\text { May also be } \\
\text { characterized by: } \\
\text { Shock/requirement of } \\
\text { vasopressors to maintain } \\
\text { blood pressure } \\
\text { Multi-organ failure } \\
\text { Evidence of myocardial } \\
\text { injury or heart failure } \\
\text { Acute kidney injury - } \\
\text { Coagulation dysfunction }\end{array}$ \\
\hline
\end{tabular}




\section{Investigations}

\section{Laboratory tests}

White blood cell counts have been reported to vary, and lymphopenia is the most common abnormal laboratory finding identified among in-patients. Leukopenia, leukocytosis, and mild thrombocytopenia are commonly seen; however, thrombocytopenia has been reported to be a poor prognostic sign ${ }^{[18-20]}$. Serum procalcitonin levels are often normal at the time of admission; however, these levels have been reported to increase in patients who require admission to the intensive care unit. High C-reactive protein, lactate dehydrogenase, alanine aminotransferase, aspartate aminotransferase, and ferritin levels might be associated with severe infection, along with high muscle enzyme and myoglobin levels, and troponin and D-dimer levels have been reported to have increased in some critically ill patients ${ }^{[18,20,27]}$.

In one study, hypokalemia was reported to be the most common laboratory finding, with $93 \%$ of severe and critically ill patients found to have hypokalemia, and $31 \%$ of the patients with severe hypokalemia also had diarrhea ${ }^{[8]}$. In children with a severe and critical illness, laboratory blood test results may show elevated levels of inflammatory factors such as interleukin (IL)-6, IL-4, IL10 , and tumor necrosis factor (TNF)- $\alpha^{[28]}$. Patients who meet the criteria for suspected cases should undergo testing for SARS-CoV-2 and other respiratory pathogens. Respiratory specimen collection from the upper and lower respiratory tracts, in particular, should be performed using strict airborne infection control precautions. Preferably, samples should be obtained as early as symptom onset, as higher viral concentrations have been reported in the early disease stage ${ }^{[29]}$. Viral culture is not recommended. Rapid molecular testing is currently being offered, and results can be obtained within $<15 \mathrm{~min}$, although the sensitivity of these tests remains to be accurately determined. However, sensitivity is likely to be $<90 \%$, depending on the assay used, the sample procurement methods, and the stage of illness. The Saudi Ministry of Health guideline recommends that nasopharyngeal swabs, involving a simple bedside procedure, should be undertaken with maximum precaution. Lower respiratory specimens (e.g. Broncho alveolar lavage) may offer superior yields, but obtaining the specimens is invasive and limited to selected patients. In one study involving 208 patients, $\operatorname{IgM}$ and $\operatorname{IgA}$ were detected within five days of symptoms appearing, whereas IgG was detected 14 days after the symptoms appeared, with a positive rate of $85.4 \%, 92.7 \%$, and $77.9 \%$, respectively. However,
COVID-19 can remain subclinical and the test results might be negative in the early or asymptomatic cases. Spirometry should be avoided due to the risk of transmission of the disease ${ }^{[30]}$.

\section{Radiology examinations}

Plain chest radiograph in the early stages of the disease is not recommended since the findings for patients with COVID-19 have typically been normal. However, if the disease has progressed with evidence of tachypnea or hypoxia, a plain chest radiograph might show evidence of bilateral air space consolidation, ${ }^{[20,31]}$. in which case a computed tomography (CT) scan should be requested urgently. The most prominent radiographic finding in the CT scan is bilateral ground-glass opacity, especially in the periphery and lower lobes. Localized infiltration, bilateral patchy infiltration, and interstitial lung infiltration have also been reported [31]. Consolidation with surrounding halo signs is a more common finding among pediatric patients and has been suggested to be a typical sign in these patients ${ }^{[31,32]}$.

\section{Bronchoscopy}

A collection of upper respiratory samples via nasopharyngeal and or pharyngeal swabs is the primary and preferred method for diagnosis. Bronchoscopy is largely contraindicated in patients with suspected and confirmed SARS-CoV-2 infections. The only role for bronchoscopy would be when less invasive testing to confirm COVID-19 is inconclusive, or when an alternative diagnosis that would affect clinical management is being suspected, or during an urgent lifesaving intervention (see below) ${ }^{[33]}$.

\section{Treatment options}

Supportive therapy is the main treatment strategy for patients with COVID-19. Treatment should be traced to assess disease progression and outcome, and the main treatment goal is to prevent the spread of infection. The therapeutic principles of treatment include general support, monitoring of lungs, liver, kidney, and myocardial functions, active control of a high fever, oxygen support, and potassium supplements if necessary [34-36].

Criteria and recommendations concerning the isolation of patients with COVID-19

-Any person diagnosed with COVID-19 infection

-Anyone who has symptoms of fever and respiratory illness, and has a history of close contact with a person who has either been diagnosed with COVID-19 or has a history of travel to a COVID-19-affected region within the last 14 days

-Any healthcare worker with symptoms of fever and respiratory illness who has been involved directly in treating patients with COVID-19, or who has had close 
contact with persons involved in treating patients with COVID- 19 during the last 14 days

-Asymptomatic patients with COVID-19 should be quarantined in their homes, and remain under strict surveillance as legally required
-A suspected patient should be isolated in wellventilated, preferably separate rooms (Figure 1).

-Symptomatic patients who are COVID-19-positive should be hospitalized in an isolated room and should be monitored by the medical team ${ }^{[36]}$.

\section{Algorithm for management of patients with suspected COVID-19}
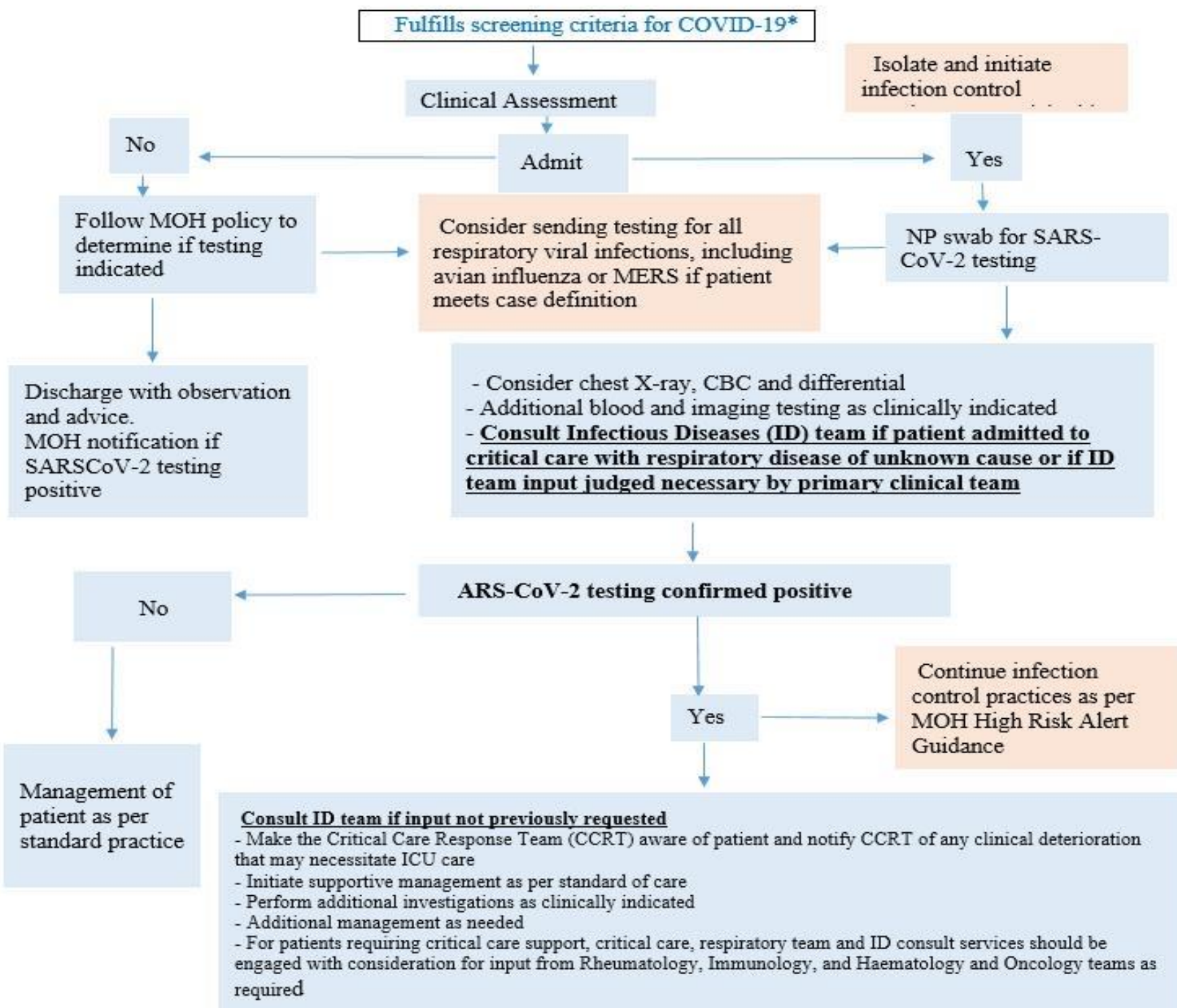

Figure 1: Algorithm for management of patients with suspected COVID19

COVID19; Coronavirus disease, MOH; Ministry Of Health, MERS; Middle East Respiratory Syndrome, NP; Nasopharyngeal, SARS-CoV-2; Severe Acute Respiratory Syndrome Coronavirus $2^{[34]}$

\section{Management options}

As of May 26, 2020, there was no proven efficacy of any drug for human use regarding to COVID-19. The following treatment options are recommended according to disease severity ${ }^{[34-36]}$.

\section{Anti-viral agents}

A large number of antiviral agents are currently being investigated, and clinical trials are underway.

-Chloroquine or hydroxychloroquine prompts direct antiviral activity to inhibit specific steps in the viral replication pathway. Impaired viral receptor 
glycosylation immune modification reduces cytokine production, especially IL-1 and IL-6. The Infectious Diseases Society of America Guidelines on the Treatment of Patients with COVID-19 recommend chloroquine or hydroxychloroquine alone or in combination with azithromycin for in-patients as a clinical trial ${ }^{[37-42]}$.

-Remdesivir has demonstrated activity against RNA viruses, including SARS-CoV-2, but it cannot be used in combination with other experimental antiviral agents. It has been reported to be widely used in Wuhan and the United States ${ }^{[43]}$.

-Lopinavir/ritonavir (LPV/RTV) has been widely used in China and elsewhere and has shown in vitro activity against SARS-CoV-2. One randomized control trial involving hospitalized patients with COVID-19 who also received other medications reported that the administration of LPV/RTV yielded no benefit. However, LPV/RTV had been administered relatively late in the disease course ${ }^{[44]}$.

Oseltamivir has been frequently prescribed regarding influenza, which is clinically similar to COVID-19; however, no known effectiveness against SARS-CoV-2 has been reported ${ }^{[2]}$.

Immunomodulators: Many agents are under consideration in clinical trials. Following previous SARS and MERS outbreaks, a monoclonal antibody against IL- 6, namely, Tocilizumab, has been recently identified as an alternative treatment for patients with COVID- 19 at risk of a cytokine storm ${ }^{[45]}$. Liu et al. reported three patients with severe COVID-19 who received high-dose intravenous immunoglobulin, with a satisfactory outcome ${ }^{[46]}$.

Steroid therapy: The administration of steroids to patients with COVID-19 remains contentious. Wang et al. reported that in 26 patients, they found an early, lowdose, short-term application of corticosteroid was associated with a more rapid improvement in clinical symptoms and absorption of lung focus ${ }^{[12]}$. Currently, steroid therapy is not recommended as per the Infectious Diseases Saudi rabia Ministry of Health guidelines ${ }^{[34]}$.

Convalescent plasma: Clinical trials are underway concerning the administration of convalescent plasma or serum-containing neutralizing antibodies against SARS-CoV-2. Information is limited and few patients have been studied ${ }^{[40]}$.

\section{Treatment recommendations according to disease severity}

Mild: Patients with mild clinical presentation might not require hospitalization, and many patients can be managed at home. The decision for hospital admission is on a case-by-case basis and should be determined according to the presence of risk factors, the home environment, patient transportation, the ability to selfisolate, and disease progression. Recommended hydroxychloroquine dosages are: Pediatric dosing: 6.5 $\mathrm{mg} / \mathrm{kg} /$ dose (max $400 \mathrm{mg} /$ dose) per mouth twice daily (PO BID) for 1 day, followed by $3.25 \mathrm{mg} / \mathrm{kg} /$ dose (max $200 \mathrm{mg} /$ dose) PO BID for 5-7 days.

Moderate: After consultation with infectious disease specialists, patients presenting with moderate COVID19 symptoms and with no evidence of hypoxia or pneumonia should be started on hydroxychloroquine and azithromycin.

Consider adding the following antiviral agents: remdesivir/lopinavir/ritonavir

Remdesivir dosing:

- $\quad$ <40 kg: $5 \mathrm{mg} / \mathrm{kg}$ loading dose; then $2.5 \mathrm{mg} / \mathrm{kg} \mathrm{IV}$ every (q) $24 \mathrm{~h}$ for $10-14$ days

- $\geq 40 \mathrm{~kg}$ : $200 \mathrm{mg}$ IV q $24 \mathrm{~h}$ for 1 day then $100 \mathrm{mg} \mathrm{IV}$ q $24 \mathrm{~h}$ for days $2-20$

Lopinavir/ritonavir dosing:

- 7-15 kg: $12 \mathrm{mg} / \mathrm{kg}$ BID for 10 days,

- 15-40 kg: $10 \mathrm{mg} / \mathrm{kg}$ BID for 10 days,

- $>40 \mathrm{~kg}$ : $400 \mathrm{mg} / 100 \mathrm{mg}$ BID for 10 days

Consider antibiotic therapy if there is a concern for secondary bacterial pneumonia.

Severe:

Patients presenting with severe COVID-19 disease require hospitalization for management. Currently no specific therapy has been approved by the United States Food and Drug Administration. Patient management involves supportive therapy for bronchopneumonia.

Criteria for severe infection include at least one of the following symptoms: respiratory rate $\geq 40$ breaths $/ \mathrm{min}$ (in children $<5$ years old), O2- saturation $\leq 93 \%$, arterial oxygen partial pressure /fractional inspired oxygen ratio $<300$, and lung infiltrates ( $>50 \%$ of the lung field within 24-48 h). Admission to the intensive care unit is indicated in such cases. After consultation with infectious disease specialists, it is recommended to start hydroxychloroquine, to consider azithromycin, and to administer a combination therapy of hydroxychloroquine with lopinavir/ritonavir. Antibiotic and antifungal therapies should also be considered.

\section{Critical:}

If a patient presents with one or more of the following symptoms, namely, ARDS, sepsis, altered consciousness, or multi-organ failure, it is recommended to treat the symptoms similarly to the treatment plan for severe patients. Administration of 
tocilizumab for cytokine release syndrome should be considered.

Criteria for patients at high risk of building up a cytokine storm

If a patient presents with one or more of the following serum IL- $6 \geq 3$ times the upper limit of normal, ferritin $>300 \mathrm{ug} / \mathrm{L}$ with doubling within $24 \mathrm{~h}$, ferritin $>600 \mathrm{ug} / \mathrm{L}$ at presentation and lactate dehydrogenase $>250$, or elevated D-dimer $(>1 \mathrm{mg} / \mathrm{L})$ levels, such patients are at high risk of building up a cytokine storm.

- Tocilizumab pediatric dosing ( $<18$ years):

- <30 kg: $12 \mathrm{mg} / \mathrm{kg}$ rehashed inside $12 \mathrm{~h}$ for a limit of 2 dosages

- $\quad \geq 30 \mathrm{~kg}: 8 \mathrm{mg} / \mathrm{kg}$ (max: $800 \mathrm{mg} /$ dose rehashed inside $12 \mathrm{~h}$ for a limit of 2 dosages) ${ }^{[34-36]}$.

\section{Prevention}

Currently, no vaccine is available, and many vaccine trials underway are in the development stage. Extensive measures to reduce person-to-person transmission of COVID-19 are required to control the current outbreak $^{[13]}$.

\section{The current situation in Saudi Arabia}

COVID-19 has been transmitted across 210 countries, with the highest number of cases approaching 1 million individuals being found in the United States. In Saudi Arabia, >76726 people have been reported to be COVID-19-positive, with Saudi Arabia listed in the $15^{\text {th }}$ position among the countries affected by COVID19.

The first reported case of COVID-19 in Saudi Arabia was on March 2, 2020, involving a Saudi national returning from Iran via Bahrain. In total, 48450 patients have recovered (63.1\% of total cases), reported active cases 27865 and the total number of COVID-19related deaths is 411 , with a case fatality of $0.5 \%$ (Figure 2 and 3).

Of these fatalities, $3 \%$ were reported in children $<14$ years old, which is higher than the number of deaths in children reported elsewhere (range, 0.8$2.2 \%$ ). The first reported death of a child in Saudi Arabia due to COVID-19-related complications was on April 25, 2020. Efforts to control the spread of COVID19 in Saudi Arabia have involved increasing the number of people tested exceeding 738,743 test, treating all patients with COVID-19 free of charge regardless of their visa or iqama (residence permit) status.

The distribution of educational materials, the closure of Mecca and Madinah (Saudi Arabia's two main holy cities) and overcrowding areas were important factors for increasing COVID-19 in certain areas, for such reason Ministry of Health $(\mathrm{MOH})$ in Saudi Arabia recommended many healthy decisions to minimize the risk of COVID-9 distribution such as avoiding overcrowding during prayers, restrictions on mobility and transportation and. On April 6, Saudi Arabia announced $24 \mathrm{~h}$ curfews implemented in the cities of Riyadh, Dammam, Tabuk, Dhahran, and Hofuf and in the governorates of Jeddah, Ta'if, Khobar and Qatif, with movement restricted to essential travel only between 6 am and $3 \mathrm{pm}$. The curfews were modified during Ramadan, which is the fasting month, to run from 9 am to $5 \mathrm{pm}$ and by end of Ramadan and during 'Eid Al-Fiter Al-Mubarak to 24 hours. Implementation of these combined extensive measures was intended to reduce the spread of SARS-CoV-2 among people residing in Saudi Arabia ${ }^{[13]}$. 


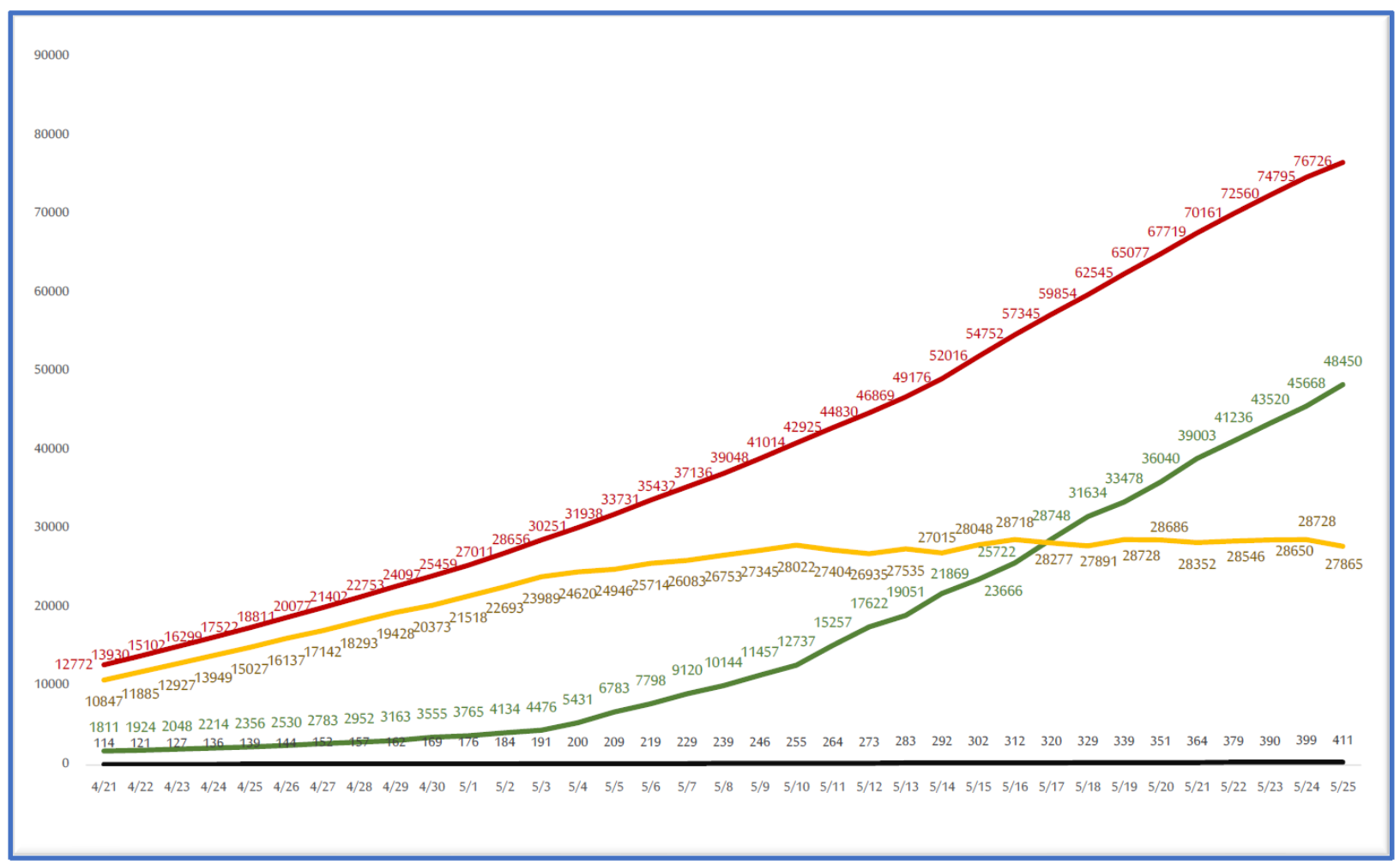

Figure 2: shows the total confirmed cases of COVID 19 in Saudi Arabia (red line), total active cases (yellow line), total recovered cases (green line), and total deaths (black line) on 2615\2020

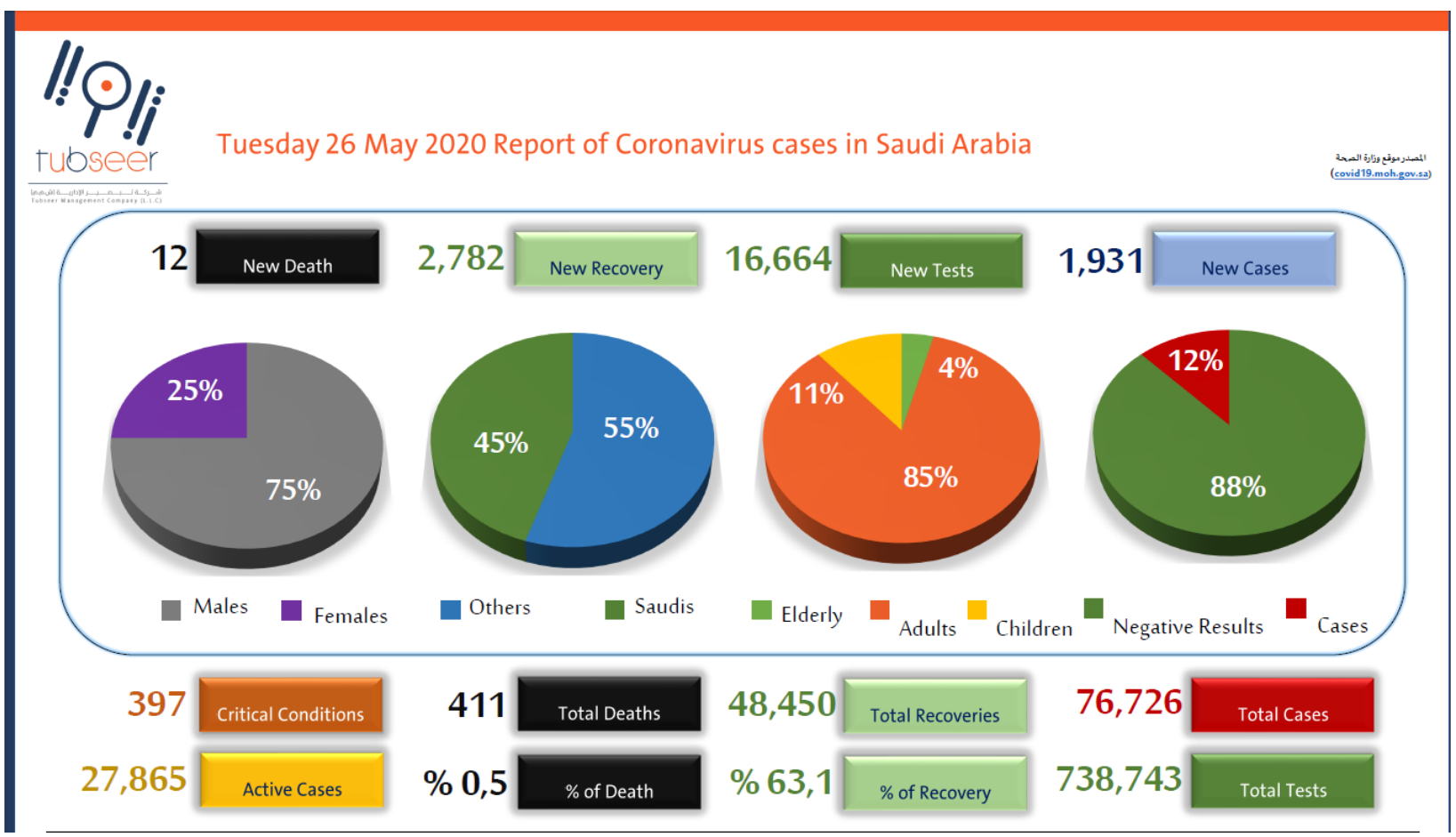

Figure 3: shows the proportion of affected adults (85\%), children (11\%), and elderly (4\%) from total cases, $55 \%$ of affected cases are Non-Saudis, and 75\% of total cases are males. (ar.tubseer.com). 
COVID-19 is a pandemic that appears to have relatively spared children. It is possible that most people infected with SARS-CoV-2 are asymptomatic. Bronchopneumonia is the main clinical presentation in symptomatic patients. There is no consistency in the clinical features of COVID-19 in children.

Patient management remains supportive, and no single medical agent has been approved for treatment as of May 26, 2020. Isolation, social distancing, and good hand hygiene are essential to reduce viral transmission. Implementation of national guidelines is recommended for medical staff, healthcare providers, and for the public health of individuals, and this remains an area of ongoing research.

\section{Declaration of Conflicting Interests:}

The authors declare no conflict of interest regarding the publication of this article.

\section{REFERENCES}

1. Zhu N, Zhang D, Wang W, Li $X$ et al. (2019): A novel coronavirus from patients with pneumonia in China, 2019. N Engl J Med., (8): 727- 733.

2. Huang $\mathrm{C}$, Wang $\mathrm{Y}$, Li $\mathrm{X}$, Ren $\mathrm{L}$, and Zhao $\mathrm{J}$ et al. (2020): Clinical features of patients infected with 2019 novel coronavirus in Wuhan, China. Lancet, (395): 497506.

3. WHO (2020): Director-General's Opening Remarks at the Media Briefing on COVID-19 - 11 March .Available online: https://www.who.int/dg/speeches/detail/whodirector-general-s-opening-remarks-atthe-media-briefingon-covid-19

4. Wu Z, McGoogan J (2020): Characteristics of and important lessons from the coronavirus disease 2019 (COVID19) outbreak in China: Summary of a report of 72314 cases from the Chinese Center for Disease Control and Prevention. JAMA., (323): 1239-1242.

5. Xia W, Shao J, Guo Y, and Peng X et al. (2020): Clinical and CT Features in Pediatric Patients with COVID-19 Infection: Different Points from Adults. Pediatric Pulmonol., (55): 24718.

6. Lu, R, Zhao X, Li J, Niu P et al. (2020): Genomic characterization and epidemiology of 2019 novel coronavirus: implications for virus origins and receptor binding. Lancet, (395):565-574.

7. Holbrook M, Gamble A (2020): Aerosol and surface stability of SARS-CoV-2 as compared with SARS-CoV-1. www.nejm.org > doi > full > NEJMc2004973

8. Wenzhong Liu 1, Hualan Li (2020): COVID-19: Attacks the 1-Beta chain of hemoglobin and captures the porphyrin to inhibit human heme metabolism. Available online: https://chemrxiv.org/articles/COVID19_Disease_ORF8_a nd_Surface_Glycoprotein_Inhibit_Heme_Metabolism_by _Binding_to_Porphyrin/11938173/5.
9. Zhang $\mathrm{W}$, Du $\mathrm{R}$, and $\mathrm{Li} \mathrm{B}$, Zheng $X$ et al. (2020): Molecular and serological investigation of 2019- Ncov infected Patients: Implication of multiple shedding routes. Emerg Microbes Infect., (9): 386- 389.

10. Rothe C, Schunk M, Sothmann P, Bretzel G et al. (2020): Transmission of 2019-nCoV infection from an asymptomatic contact in Germany. New Eng J Med., (382): 970-971.

11. Chen H, Guo J, Wang $C$, and Luo F et al. (2020): Clinical characteristics and intrauterine vertical transmission potential of covid- 19 infection in nine pregnant women: A retrospective review of medical records. The Lancet, (395): 809-815.

12. Alasdair P, Saul N (2020): Children are not COVID-19 super spreaders: time to go back to school. Arch Dis Child., $0: 1-2$.

13. Saudi center for disease control and prevention (2020): https://www.moh.gov.sa/CCC/healthp/regulations/Docum ents/Coronavirus\%20Disease\%202019\%20Guidelines\%2 0v1.1..pdf , https://covid19.cdc.gov.sa/ar/daily-updatesar/.

14. Guan Q, Wu P, Wang $X$ et al. (2020): Early transmission dynamics in Wuhan, China, of novel coronavirus-infected pneumonia. N. Engl. J. Med., (382): 1199-1207.

15. Wang D, Hu B, Hu C, Zhu F et al. (2020): Clinical characteristics of 138 hospitalized patients with 2019 novel coronavirus-infected pneumonia in Wuhan, China. JAMA., (323): 1061-1069.

16. Chen N, Zhou M, Dong X, Qu J, and Gong F et al. (2020): Epidemiological and clinical characteristics of 99 cases of 2019 novel coronavirus pneumonia In Wuhan, China: a descriptive study.Lancet, (395): 507-513.

17. Xu X, Wu X, Jiang $X$, and $X u K$ et al. (2020): Clinical findings in a group of patients infected with the 2019 novel coronavirus (SARS-Cov-2) outside of Wuhan, China: Retrospective case series. BMJ., (368): 606.

18. Guan WJ, Ni ZY, Hu Y, and Liang W et al. (2020): Clinical characteristics of coronavirus disease 2019 in China. N Engl J Med., (382): 1708-1720.

19. Wenjun D, Jinhong $Y$, Hui $W$, Xiaoguo $Z$ et al. (2020): Clinical characteristics of COVID- 19 in children compared with adults in Shandong Province, China. https://doi.org/10.1007/s15010-020-01427-2.

20. Qiu H, Wu J, Liang H, Yunling L, Song Q, and Chen D et al. (2020): Clinical and epidemiological features of 36 children with coronavirus disease 2019 (Covid-19) In Zhejiang, China: An observational cohort study. Lancet Infect Dis., (388):490-494.

21. Lara S, Nabihah R, Katie Ket al. (2020): Characteristics and Outcomes of Children with Coronavirus Disease 2019 (COVID-19) Infection Admitted to US and Canadian Pediatric Intensive Care Units. jamanetwork.com > journals > jamapediatrics > fullarticle

22. Dong $Y$, Mo $X$, Hu Y, and Qi $X$ et al. (2020): Epidemiological characteristics of 2143 pediatric patients with 2019 coronavirus disease in China. Pediatrics,2020. 
23. Wei M, Yuan J, Liu Y, and Fu T et al. (2020): Novel coronavirus infection in hospitalized infants under 1 year of age in China. JAMA., (305):2131.

24. Kelvin A, Halperin S. (2020): COVID-19 in children: The link in the transmission Chain. Lancet Infect Dis., 1473-3099(20):30236-x.

25. Yang W, Cao Q, Qin L, Wang X et al. (2020): Clinical characteristics and imaging manifestations of the 2019 novel coronavirus disease (Covid-19): A multi-center study in Wenzhou city, Zhejiang, China. Journal Infect., (80):388-393.

26. Yan Chen, Hua Peng, Lin Wang, and Yin Zhao et al. (2020): Infants born to mothers with a new coronavirus (COVID-19). doi:https://doi.org/10.3389/fped.2020.00104.

27. Zhou F, Yu T, Du R, Fan G et al. (2020): Clinical course and risk factors for mortality of adult inpatients with covid19 in Wuhan, China: A retrospective cohort study. Lancet, 395: 1054-1062.

28. National Health Commission of the People's Republic of China(2020): Diagnosis and treatment plan of novel coronavirus pneumonia (Version 7) [EB/OL].http://www.nhc.gov.cn/yzygj/s7653p/202003/46 c9294 a7dfe4cef80dc7f5912eb1989.shtml

29. Case definition and European surveillance for COVID19(2020): Available online: https://www.ecdc.europa.eu/en/case-definition-andeurope an-surveillance-human-infection-novelcoronavirus-2019-nco.

30. https://ginasthma.org/wpcontent/uploads/2019/06/GINA-2019-main-reportJune-2019-wms.pdf

31. Ma HJ, Shao J, Wang Y, and Aiguo Z et al. (2020): High resolution CT features of novel coronavirus pneumonia in children. www.ncbi.nlm.nih.gov, pmc, articles , PMC7156230

32. Xia W1, Shao J, Guo Y, Peng X, Li Z, Hu D (2020): Clinical and CT features in pediatric patients with COVID19 infection: Different points from adults Pediatric Pulmonol., doi: 10.1002/ppul.24718.

33. Momen M, Carla L, Septimiu M et al. (2020): American Association for Bronchology and Interventional Pulmonology (AABIP) Statement on the Use of Bronchoscopy and Respiratory Specimen Collection in Patients with Suspected or Confirmed COVID-19 Infection..ncbi.nlm.nih.gov > pubmed

34. Saudi MoH Protocol for Patients Suspected of/Confirmed with COVID-19(2020): Available online: https://www.moh.gov.sa/Ministry/MediaCenter/Publicatio ns/Documents/MOH-therapeutic-protocol-for-COVID-19.
35. Stanford guideline Coronavirus, COVID-19, SARS (2020): webedition.sanfordguide.com > coronavirus

36. Infectious Diseases Society of America (2020): Guidelines on the Treatment and management of patients with COVID-19. Available online at: https://www.idsociety.org/practice-guideline/covid-19guideline-treatment-and-management.

37. Chen Z, Hu J, Zhang Z, Jiang S et al. (2020): Efficacy of hydroxychloroquine in patients with COVID-19: Results of a randomized clinical trial. Med Rxiv., (03):22.

38. Chen J, Liu D, Liu L, Liu P et al. (2020): A pilot study of hydroxychloroquine in treatment of patients with common coronavirus disease-19 (COVID-19). J Zhejiang Univ Sci B., 49: 215-219.

39. Gautret $P$, Lagier JC, Parola $P$, Hoang $V$ et al. (2020): Hydroxychloroquine and azithromycin as a treatment of COVID-19: Results of an open-label non-randomized clinical trial. Int J Antimicrob Agents., 10: 1016

40. Gautret $P$, Lagier JC, Parola $P$,Hoang $V$ et al. (2020): Clinical and microbiological effect of a combination of hydroxychloroquine and azithromycin In 80 COVID-19 patients with at least a six-day follow up: An observational study. Travel Med Infect Dis., (34):101663.

41. Molina JM, Delaugerre C, Goff J ,Mela-Lima B et al. (2020): No evidence of rapid antiviral clearance or clinical benefit with the combination of hydroxychloroquine and azithromycin in patients with severe COVID-19 infection. Méd Mal Infect., (50): 384.

42. Chorin E, Dai M, Shulman E, Wadhwani L et al. (2020): The QT interval in patients with SARS-CoV-2 infection treated with hydroxychloroquine/azithromycin. medRxiv https://doi.org/10.1101/2020.04.02.20047050

43. Welliver R, Monto AS, Carewicz O, and Schattman E et al. (2001): Effectiveness of oseltamivir in preventing influenza in household contacts: A randomized controlled trial. JAMA.,285:748-754.

44. Cao B, Wang Y, Wen D, Liw W et al. (2020): A Trial of lopinavir-ritonavir in adults hospitalized with severe COVID-19. N Engl J Med., 382: 1787-1799.

45. Xu X, Han M, Li T, Sun W et al. (2020): Effective treatment of severe COVID-19 patients with tocilizumab. ChinaXiv.,3:26v1.

46. W Cao, Liu X, Bai T, Fan H et al. (2020): High-dose intravenous immunoglobulin as a therapeutic option for deteriorating patients with coronavirus disease 2019. doi: 10.1093/ofid/ofaa102.

47. Shen $C$, Wang Z, Zhao F, Yang $Y$ et al. (2020): Treatment of 5 critically ill patients with COVID-19 with convalescent plasma. JAMA., (323): 1582-1589. 